\title{
A Boundedly Rational Analysis of Global Distributive Justice
}

Alexandru VOLACU ${ }^{1}$, National School of Political and Administrative Studies, Romania Iris-Patricia GOLOPENTA², National School of Political and Administrative Studies, Romania

\section{Abstract}

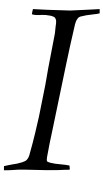

$n$ the present paper we analyze two prominent global distributive justice theories, i.e. Pogge's Global Resource Dividend theory (1994) and Dorsey's maxificing welfarism (2005) under an assumption of bounded rationality. We consider that the agencies responsible for distributing resources are informationally constrained in regard to the assessment of economic positions in society and cognitively constrained in regard to the decision making process within the agency. We argue that under these conditions the distributive patterns prescribed by both theories can be severely distorted. Further, in Dorsey's case bounded rationality can even lead to a complete failure of the theory, since not only are the resulting distributions sub-optimal if we introduce the possibility for a single mistake in the identification process, but they can also be completely redundant by prescribing distributions which are not capable of lifting a single citizen to the minimum level required for the fulfillment of basic needs. We further show that for both theories the identification problem becomes more severe and that the agencies are more susceptible to make mistakes in circumstances of extreme poverty, i.e. the circumstances primarily targeted by the theories. Aside from this main result, we also obtain three secondary results: 1. we extend the ongoing debates in political philosophy between ideal and non-ideal theories and in particular between factinsensitivity and fact-sensitivity, 2. we provide a preliminary defense of a proportional distributive principle for global justice and 3. we provide a new starting point for the construction of arguments regarding the nature of the agency (e.g. global government, national governments, UN institutions, international NGOs) entitled to distribute resources in global justice theories.

\footnotetext{
${ }^{1}$ Alexandru Volacu is a $2^{\text {nd }}$ Year MA student in Political Theory and Analysis at the Faculty of Political Science, National School of Political and Administrative Studies, Bucharest, Romania. He is a member of IAPSS since 2009. He has previously published scientific articles on political philosophy and political science in the Romanian Journal of European Affairs, the Romanian Journal of Society and Politics, Revista de Stiinte Politice. Revue des Sciences Politiques, Perspectives in Politics and the Sphere of Politics. His main research interests include: Political Philosophy, the Philosophy of Science, Public Choice Theory, Game Theory, Spatial Analysis and Political Ethics.

E-mail address: volacu@gmail.com
}

${ }^{2}$ Iris-Patricia Golopenta is a $2^{\text {nd }}$ Year MA student in Political Theory and Analysis at the Faculty of Political Science, National School of Political and Administrative Studies, Bucharest, Romania. She is currently an intern at Romanian Academic Society. Her research interests include: Normative Theory, Political Philosophy, Ethics, Institutional Approaches of Political Science and Gender Studies.

E-mail address: irisgolopenta@yahoo.com 
Keywords: bounded rationality, distributive agency, distributive pattern, Dorsey, global distributive justice, nonideal theory, Pogge

Motto: "Should the facts be allowed to spoil a good theory?" (Lovell, 1986, p.120)

\section{Introduction}

$\mathrm{E}$ ver since Rawls's (1993) first important contribution to global justice theories, the field has become one of the most fertile debate forums in political philosophy. Theories of global distributive justice ${ }^{3}$ also share a common root with the Rawlsian line of thought, with some of the most important theories in this strand being considered extensions of the difference principle (see Rawls, 1971, p.72), although Rawls himself opposed such a view by stating that "the principles of justice for the basic structure of society are not suitable as fully general principles. They do not apply to all subjects $[\ldots]$ or to the law of the peoples” (Rawls, 1993, p. 39). Instead, Rawls argues that they should be systematically constructed by a procedure that modifies

3 Among the prevalent cosmopolitan defenders of global distributive justice we can find, inter alia, Pogge (1994), (2001), (2002), Beitz (1979), (2000), Barry (1999), Mollendorf (2002), Tan (2004). Some of its prominent critics (which mostly defend Rawls' conception of global justice) include: Rawls (1993), (1999), Dworkin (2000), Reidy (2004), Nagel (2005). This list does not even begin to scratch the surface of the literature in question but it does manage to briefly outline some of the most important contributions. and adapts to the nature of the situation each time the parties are required to agree on the principles of fair distribution and cooperation.

One of the main characteristics of global distributive justice theories is that they do not take into account a significant number of empirical circumstances, which when considered, could completely alter the distributive patterns of the theory. We argue that one such circumstance is the fact that human beings are cognitively and informationally constrained, or in Simon's terms boundedly rational (1976), and that as a consequence they will not be able to accurately identify in all instances the members to which they should distribute goods if they follow a prescribed distributive pattern. Our purpose in this paper is to show that for at least two theories of global distributive justice, one which follows the mainstream position of extending the difference principle to a global framework, i.e. Pogge's GRD approach (1994) and one which is derived on a consequentialist basis, i.e. Dorsey's maxificing welfarism (2005), the prescribed patterns of distribution are susceptible to lead to perverse outcomes. 
The paper is divided into seven parts, excluding the introduction. In the first two parts we present a brief overview of the theories of global distributive justice as developed by Pogge and Dorsey. In the third part we present a brief overview of the concept of bounded rationality and explain the sense in which it will be used in the paper. In the fourth part we explain the general context in which the bounded rationality assumption is relevant for political philosophy, namely the debates between ideal theories and non-ideal theories, and in particular between factinsensivity and fact-sensitivity. In the fifth part we explain the distributive patterns prescribed by Pogge and Dorsey by capturing them in a common structural framework. In the sixth part, where the bulk of our argument is concentrated, we show what effects the introduction of a bounded rationality assumption could have on the distributive patterns prescribed by Pogge and Dorsey. In the final part we draw the conclusions of the paper and lay the groundwork for potential discussions which could stem from the present paper but were not included here due to spatial constraints or due to the different scope of the paper.

\section{Global distributive justice - Pogge and Dorsey's perspectives}

2.1. Pogge's GRD approach to global distributive justice
According to Pogge, the present global order is characterized by political and economical interdependency that is very likely to persist in the future. Hence he expresses three egalitarian concerns regarding the deficiencies in mitigating inequalities: 1. citizens of different nations benefit from unequal chances to influence the transnational political decisions, 2 . equally talented and motivated individuals do not possess equal chances to obtain public goods, services and positions, regardless of their nation of origin and 3 . social and economic inequalities are not used in the benefit of the world's worst off positions. (Pogge, 1994, p.196) These three observations are substantially compatible with Rawls's two principles of justice that state the following: 1) "each person is to have an equal right to the most extensive scheme of equal basic liberties compatible with a similar scheme of liberties for others" (Rawls, 1971, p.53) and 2) "social and economic inequalities are to be arranged so that they are both (a) to the greatest expected benefit of the least advantaged and (b) attached to offices and positions open to all under conditions of fair equality of opportunity" (Rawls, 1971, p.72).

Given the similarities, the questions that naturally rise are whether the Rawlsian original position could be applied to the international order in all its complexity and how should it be constructed on a meta- 
theoretical perspective? The specialized literature identifies several answers to these questions. Rawls discusses two possibilities: 1. initially the principle of justice is applied to the basic structure of each society and subsequently in a second round of negotiations between the state's representatives in order to construct international principles of justice or 2 . the application of a single-step process under the form of a global original position. Pogge (1994), argues in favor of the first option as it seems to comply with the egalitarian concerns formulated above and he uses it in order to both clear the methodological background of his research and also defend his conception of global justice: "what is needed is a principle that asses alternative global economic orders in terms of their distributive effects, just as his [Rawls'] principle assesses alternative ways of structuring a national economy" (Pogge, 2001, p. 16).

He basically criticizes Rawls's lack of precision in arguing about the nations and its borders and is trying to counter the following highly-idealized case: "there really is a clear-cut distinction between peoples and other kinds of groupings, that every person belongs to exactly one people, and that each national territory really does, nearly enough, contain all and only the members of a single group" (Pogge, 1994, p.197). Pogge addresses the problem of national borders not as historically arbitrary limits of states as Rawls does, but rather as the result of violence and coercion. Thus, their distributional significance, as they determine the contextual life of individuals benefiting and controlling its land and all its natural resources is not justified. Therefore, the affluent states and its citizens who unconditionally benefit from public goods and open positions, development and resource opulence have the moral responsibility to offer foreign aid to those who are dealing with daily poverty, mortality and malnutrition and support the universalization of human rights to a "standard of living adequate for the health and well-being of oneself and one's family, including food, clothing, housing and medical care" ${ }^{4}$. Moreover, the moral duty of these states is even greater since they are directly responsible not just for alleviating poverty, but also for perpetuating it, taking into account the role and rationale off some of the international economic institutions that have been founded and consolidated particularly at the initiative of these states (Pogge, 2001, p. 15).

How can foreign aid as duty of the global economic order be transposed into proper mechanisms to justify the state's

${ }^{4}$ The Universal Declaration of Human Rights, accessed at: http://www.ohchr.org/EN/UDHR/Docu ments/UDHR Translations/eng.pdf, at 19.02.2013. 
negative responsibility towards the other states? Pogge formulates one institutional proposal, i.e. the Global Resource Dividend ${ }^{5}$ (GRD) that could be interpreted as a type of difference principle and may be successfully defended by an egalitarian conception of international justice. The GRD implies that people should pay a proportional tax on the resources $^{6}$ they extract from the territory within its national borders, weather they use it themselves or export it. The GRD is therefore a consumption dividend that discriminates between the amount of the taxes, proportionally to how much value each takes from our planet (Pogge, 1994, p. 199) and automatically leads to higher prices for natural resources. Pogge argues that the dividend could be interpreted as a sort of Lockean proviso, with the mention that the dividend does not bear the proviso's lack of precision, on the contrary: anyone can enjoy the earth's resources to the fullest, but in return must share some economic benefit. The amount of money shall therefore be used by the governments in mitigating the socio-economic global inequalities and directly offered as aid to the poor countries, based both on their per capita income and population size (Pogge, 1994, p. 1999).

5 In a previous paper called the Global Resource Tax (Pogge, 1994, p. 199).

${ }^{6}$ Pogge does not limit the concept of national resources just to land, but extends it to water, infrastructure, education and even air.
Pogge also identifies 4 problems that the GRD must confront, which are as follows: 1. the risks of establishing prohibitive taxes and block economic sectors of states, 2 . the dividend imposed on the cultivation of basic commodities might lead to increasing their prices, which will negatively affect the worst-off positions, 3 . the necessity to anticipate the worst-off positions of the future and therefore overtax the limited resources of the world or the highly dangerous pollutants and 4. the tax should be based on resources and pollutants whose extraction should be easily monitored and estimated. (Pogge, 1994, p. 204)

The issue of global poverty could therefore be approached and solved if the interdependencies of the world were perceived in a constructive perspective: the affluent countries are due to expand their advantages and enter into a global bargaining process with the other countries, while the poor are due to accept the economical, technological and know-how abilities that the rest posses in their advantage. Hence, the GRD could be a proper instrument to try.

\section{2.. Dorsey`s maxificing welfarism}

An alternative perspective on how global justice should be achieved is entertained by Dale Dorsey who argues 
against human rights ${ }^{7}$ as a main justifying instrument for achieving global justice, for "this language cannot form a plausible foundation for international obligations and [...] although some thinkers claim that they posses powerful rhetorical appeal and thus might profitably be used to mobilize action designed to reduce or eliminate suffering, human rights are not sensitive to the concerns of justice that exist in recipient nations" (Dorsey, 2005, p. 562). Dorsey develops a bilateral approach, focusing both on the obligations that the rich countries have to the poor ones, but also on the domestic justice of the second, meaning the proper way that their national institutions ought to be organized to account for a particular conceptions of justice. Actually, the concern regarding the internal framework of justice and its consistency with the nature and type of international aid is essential, for any kind of intervention would be prone to fail if they completely neglect the domestic circumstances of justice. For instance, in the very poor countries, in the midst of crises or a powerful famine, fair distribution could not possibly be achieved according to Rawls's difference principle, for prioritizing the worst-off implicitly means decreasing the goods for the ones that are barely able to avoid starvation and creating a greater harm.

\footnotetext{
${ }^{7}$ Even the basic rights that assure human needs, in the manner that Pogge argues.
}

The human rights approach would have argued in favor of the distribution that attempted to ensure a basic level of needs to all citizens, because no governmental action or institution is legitimized to infringe on their rights, as possession of basic needs is considered to be an obligation and forms a side-constraint on the social policy (Dorsey, 2005, p. 568). However, according to Dorsey, when dealing with deprivation, starvation or severe poverty, this approach fails.

Dorsey's main hypothesis is "that many theories of justice are unable to capture $[. .$.$] is that fulfilling basic needs has$ priority" (Dorsey, 2005, p. 566). Thus, survival is the goal of legislators in very poor countries and rights are violable only when the benefit is great enough and there are enough individuals who could be saved (Dorsey, 2005, p. 571). Otherwise stated, Dorsey does not avoid at all the concept or rights, but more likely seeks to maximize their fulfillment (Dorsey, 2005, p. 572) instead of arbitrary distributing between individuals - and calls this way of reasoning maxificing. However, the theory is incomplete because it fails to respond to a minimum of two aspects: 1) situations in which resources are left over and all have been brought up to the sufficient level (Dorsey, 2005, p. 578) 2) situations in which resources are left over, but are not enough to bring any further persons to the sufficient level. (Dorsey, 
2005, p. 578). Thus, in Dorsey's view, global justice should not be concerned with human rights, but with the desiderata of assuring the level of living decency for the greatest number of individuals.

\section{The importance of bounded rationality} for theories of global distributive justice

\subsection{Bounded rationality - an overview}

For a long time mainstream economic theories as well as their applications in non-economic fields (e.g. public choice theory, the economic analysis of law, the new economic history) upheld a tradition of adopting the "homo economicus" view or phrased in other terms, "comprehensive rationality", (Jones, 1999, p.299) as a core assumption. However, some authors argue that "the fully rational man is a mythical hero who knows the solutions of all mathematical problems and can immediately perform all computations, regardless of how difficult they are. Human beings are very different. Their cognitive capabilities are quite limited. For this reason alone the decision behavior of human beings cannot conform to the ideal of full rationality" (Selten, 1999, p.3). At least five

\footnotetext{
${ }^{8}$ Jones identifies the following assumptions which cumulatively characterize comprehensive rationality: 1 .preferences are defined over outcomes, 2 . the outcomes are known and fixed and 3. decision-makers maximize their utilities by choosing the alternative that yields the highest level of benefits (Jones, 1999, p.299).
}

main objections to adopting a comprehensively rational view of human nature can be brought: 1. even casual empiricism leads to the conclusion that even in quite simple decision problems, most economic agents are not maximizers, i.e. do not scan the choice set and consciously pick a maximal element from it, 2. maximizations of this type are sufficiently difficult to prevent people from acting as in this way in most practical situations, even if they have maximizing intentions, 3. polls and experiments widely confirm that individuals fail to conform to at least some of the rational choice postulates, 4. laboratory experiments show that the conclusions of analysis based on strong rationality assumptions are unrealistic and 5. the conclusions of rational analysis sometimes seem unreasonable even on the basis of simple introspection (Aumann, 1997, p.2).

In order to counter many of the deficiencies met in models based on comprehensive rationality, Simon introduces the concept of bounded rationality, which places limits on both an individual's "ability to perform" and on his "ability to make correct decisions" (Simon, 1976, p.39), since they act in a "world of limited epistemic, cognitive, and analytical opportunities" (Sen, 1997, p.768). Simon's basic idea is then to "replace the global rationality of economic man with a kind of rational behavior that is compatible with the access to information 
and computational capacities that are actually possessed by organisms, including man, in the kinds of environments in which such organisms exist" (Simon, 1955, p.99). A way to understand the concept of bounded rationality, in particularly in respect to informational and cognitive constraints ${ }^{9}$, is by following Lipman's (1995, p.42) interpretation of agents as information processors. In this view, the agent receives inputs (information external to the individual) and generates outputs (decisions) after processing the former. In this framework, bounded rationality would therefore refer to "choice that is imperfect in the sense that the output is often not the 'correct' one, but is sensible in that it can be understood as an attempt by the agent to do reasonably well. Put differently, the procedure used is a reasonable compromise between accuracy of the output and the difficulties involved in processing" (Lipman, 1995, p.43).

The reason why we argue that taking into account the constraints mentioned in the preceding paragraph, in the form of a bounded rationality assumption, is important is that its empirical plausibility has repeatedly been confirmed in experimental situations starting from the pioneering work of Tversky and Kahneman (1974), (1979) and continuing with many other similar results

9 Which is the dimension of bounded rationality in which we are interested here. (for overviews of studies favoring the empirical superiority of bounded rationality to strict views of rationality see, inter alia, Conlinsk, 1996, Camerer, 1998 and Selten, 1998). We therefore consider that following the considerable amount of proof which supports the bounded rationality hypothesis, its incorporation into global distributive justice theories is justified, as these sorts of theories are economic by construction, albeit normative, especially when we view economics as the study of "rational allocation of scarce resources" (Simon, 1978, p.2).

\subsection{Bounded rationality as a step} towards building non-ideal theories of global distributive justice

Before examining the effects which the introduction of a bounded rationality assumption would have on the distribution of goods in the two theories previously described, we consider it necessary to take a short meta-theoretical detour in order to explain the larger picture in which this discussion takes place. This conceptual field is represented by the on-going debate between ideal theorists and non-ideal theorists with respect to the relevance of taking into account certain types of constraints in normative theory-building. The distinction between ideal and non-ideal theory with regard to normative assessments of justice is first discussed by Rawls (1971, 
p.8) who frames his theory of justice as fairness within the framework of ideal theory, assuming that the parties will comply in all cases with the principles established in the original position. In the initial meaning introduced by Rawls, ideal theory differs from non-ideal theory in that the former "attempts to describe those principles for the design of institutions and the conduct of persons that would be appropriate to a morally and politically ideal order, while non-ideal theory concerns itself with the principles that would be appropriate for these purposes under less perfect conditions" (Phillips, 1985, p.551). The main element of disagreement between the two approaches is therefore exclusively axiological, being reduced to the universal following of moral constraints by individuals.

The current debate focused on the subject is however decidedly more complex ${ }^{10}$ introducing several other dimensions complementary to the full compliance one, namely the distinction between idealization and abstraction ${ }^{11}$, the distinction between a

\footnotetext{
${ }^{10}$ For a basic introduction to the main issues in question see Farrely (2007), Simmons (2010), Valentini (2012) and Hamlin and Stemplowska(2012).

${ }^{11}$ Idealization is understood as the "making of false assumptions about some significant aspect of the problem in hand", while abstraction is "understood to consist in ignoring or bracketing off some complexities of a given problem, but without assuming
}

theory of perfect justice (or a transcendental theory) and a theory of local improvement in justice (or a comparative theory) ${ }^{12}$ and the distinction between fact-sensitivity and factinsensivity (Hamlin and Stemplowska, 2012, pp.3-6). The last distinction, which specifies whether the theory is empirically constrained on any level, is the one in which we are primarily interested in this paper. As Farrelly (2007) points out, Rawls himself takes into account some moderate constraints when constructing his original position, such as pluralism or the human nature as well as others, e.g. moderate scarcity ${ }^{13}$, but that many other constraints, such as unfavorable historical, social or economic conditions, indeterminacy, fallibility, human vulnerability, problems of institutional design, etc. are not included in the assumption set of the theory of justice as fairness, further arguing that the theory itself is unrobust when some of these assumptions are altered (Farrelly, 2007, p.847). If we adopt the view made explicit by Hamlin and

any falsehoods about them" (Hamlin and Stemplowska, 2012, p.4).

${ }^{12}$ A transcendental theory "focuses on identifying perfectly just social arrangements while a comparative theory concentrates on ranking alternative social arrangements" (Hamlin and Stemplowska, 2012, p.6). Hamlin and Stemplowska underline however that the transcendental-comparative dimension doesn't in their view perfectly correspond to the ideal-non-ideal categories. ${ }^{13}$ Although Farrelly specifically targets the explicit introduction of moderate scarcity as a constraint arguing that in effect he fails to take it into account (2007, pp.848-856). 
Stemplowska, that the distinction between ideal and non-ideal theory is a fuzzy one and it should be interpreted on a continuum rather than through a categorical approach (2012, p.3), then Rawls' theory of justice as fairness is not placed on either extreme, although it is somewhat closer to the factinsensitive extreme ${ }^{14}$ and the same can be said of Pogge and Dorsey's theories previously discussed, since they take into account certain constraints such as extreme resource scarcity (Dorsey, 2005, p.565) or even non-compliance (Pogge, 1994, p.202), but not others such as the limits of human nature.

The introduction of bounded rationality as a constraint in theories of global distributive justice is therefore a step forward in the attempt to ground the normative principles derived through their usage in empirical facts and move the theories towards a non-ideal perspective. There are at least two reasons why we consider it necessary to follow this course of

\footnotetext{
${ }^{14}$ On this extreme position we could place, as Farrelly (2007, p.847) does, Cohen's approach, who argues in favor of complete fact-insensivity in deriving normative principles by stating that "a principle can reflect or respond to a fact only because it is also a response to a principle that is not a response to a fact. To put the same point differently, principles that reflect facts must, in order to reflect facts, reflect principles that don't reflect fact"' (Cohen, 2003, p.214). On the opposite extreme we could place any normative theory which is fully grounded in empirical circumstances.
}

action. First of all we agree in general with Farrelly's remark that the bracketing of certain real-life constraints in some theories of justice ${ }^{15}$ severely limits or even distorts the results of the theories in their practical application (Farrelly, 2007, p.859). Secondly, we argue that an even stronger argument can be brought in support of our enterprise, namely one which starts from Rawls' (1999) own transcendental position and more specifically from his claim that a theory of global justice should be realistically utopian $^{16}$. The argument is constructed as follows: the fact-sensitive constraint set can broadly be described as consisting of three types of categories: 1. elements which are historically derived, e.g. unfavorable circumstances generated by colonization, 2 . elements which are morally derived, e.g. quasi-full compliance or 3. elements which are physically derived, e.g. cognitive limitations. The problem with non-ideal theorizing under historical or moral constraints is that there is a possibility that in future scenarios we may come to respect a principle derived under constraints which are no longer valid and would therefore be

\footnotetext{
${ }^{15}$ Farrelly directs his own criticism at liberal egalitarianism but it can also be applied on principle to global distributive justice theories.

${ }^{16}$ Rawls states that a normative theory is "realistically utopian" when it extends what are ordinarily thought to be limits of practicable political possibility and, in so doing, reconciles us to our political and social condition” (Rawls, 1999, p.11).
} 
sub-optimal. However, since we have adopted a transcendental stance we cannot simply argue that at some point in time we will re-evaluate the social arrangements made, because we are ab initio in the position to seek perfectly just social arrangements, which are atemporal. But because bounded rationality is a physical characteristic of individuals we cannot presume that there is a foreseeable future populated by individuals with similar physical characteristics, where the constraint might be altered, therefore, the risk of principles becoming sub-optimal at some point does not exist. The objection which could be therefore brought against the first type of constraints, i.e. that they are not utopian in the Rawlsian sense (Rawls, 1999, p.14) cannot be brought against the bounded rationality constraint. Further, as the assumption of bounded rationality is a part of human nature, it is required by a theory which seeks to be realistic even under Rawls' own view (see Rawls, 1999, p.13). Thus, we conclude the argument by stating that the introduction of bounded rationality in theories of global justice is not only requested by meta-theoretical conceptions in line with non-ideal theory, but that it is also required in the original transcendental framework of a Rawlsian realistic utopia.

\section{Distributions under the assumption of} bounded rationality

\subsection{Distribution beneficiaries in Pogge and Dorsey's approaches}

As we mentioned in the introductory part of this paper, our objective is to discuss global distributive justice theories from the perspective of a specific component, namely the pattern of distribution prescribed by the theories. All distribution mechanisms broadly adopt the following structure: citizens from category $\mathrm{X}=\left\{\mathrm{x}_{1}, \mathrm{x}_{2}, \mathrm{x}_{3}, \ldots, \mathrm{x}_{\mathrm{i}}, \ldots \mathrm{x}_{\mathrm{n}}\right\}$ are taxed by institution (or agency) I and the goods extracted are being redistributed to citizens from category $\mathrm{Y}=\left\{\mathrm{y}_{1}, \mathrm{y}_{2}, \mathrm{y}_{3}, \ldots, \mathrm{y}_{\mathrm{i}}, \ldots \mathrm{y}_{\mathrm{n}}\right\}^{17}$, on the basis of a set of conditions $\mathrm{C}=\left\{\mathrm{c}_{1}, \mathrm{c}_{2}, \mathrm{c}_{3}, \ldots, \mathrm{c}_{\mathrm{i}}, \ldots \mathrm{c}_{\mathrm{n}}\right\} . \quad$ The main objective of a significant part of distributive justice theories ${ }^{18}$ is therefore to provide arguments justifying why a certain condition $^{19}$ from set $\mathrm{C}$ must be the determinant factor in the redistribution of goods from $\mathrm{X}$-type citizens to Y-type citizens, while also specifying certain other aspects such as the trigger and stopping mechanisms for the redistribution (if such mechanisms exist), the type of goods to be redistributed, the level of goods which are to be redistributed, etc.

\footnotetext{
${ }^{17}$ In an informal language, we can state that the $X$-type citizens are net contributors to the redistribution while $Y$-type citizens are net beneficiaries.

${ }^{18}$ Including the approaches of Pogge and Dorsey.

${ }^{19}$ Or a subset of conditions.
} 
By looking at the two global distributive justice theories examined here through this lens we can fix them in a common framework which we will use in the next part in order to more easily explain their shortcomings. The first of these theories, namely Pogge's GRD proposal, states that the rules governing the distributions should be conceived in such a way so that "the entire GRT scheme has the maximum possible positive impact on the world's poorest persons -the poorest quintile, say- in the long run" (Pogge, 1994, p.203). We can notice that this can basically be understood as the difference principle, i.e. "social and economic inequalities are to be arranged so that they are to the greatest expected benefit of the least advantaged" (Rawls, 1971, p.72), applied on a global scale but focusing solely on economic issues ${ }^{20}$. In Pogge's view, set $\mathrm{C}$ consists of a single condition, let us call it $\mathrm{c}_{\mathrm{P}}$, which is that a distribution is justified when it is to the greatest advantage of citizens from $Y_{P}$, where $Y_{P}$ is the set of citizens which are,

\footnotetext{
${ }^{20}$ Freeman (2007) argues that in fact a global distributive principle cannot be the Rawlsian difference principle since the latter is a political principle which is predicated on the existence of both a system of property and a legal system which are common for the agents to which it applies. In the absence of such systems, which is characteristic to the global environment as a whole, Freeman argues that any principle of distributive justice cannot be anything more than a simple reallocation model (2007, p.444).
}

from an economic standpoint, worse-off. Thus, it can be said that $\mathrm{y}_{\mathrm{i}}<\mathrm{x}_{\mathrm{i}},(\forall) \mathrm{y}_{\mathrm{i}} \in \mathrm{Y}_{\mathrm{P}}, \mathrm{x}_{\mathrm{i}} \in \mathrm{X}_{\mathrm{P}}$.

In Dorsey's maxificing welfarism, the distribution condition, which we will term $c_{D}$, radically differs from $c_{P}$. Dorsey argues that "the main concern of the government should be to alleviate poverty for the greatest number possible" (2005, p.565) and that "the maximal fulfillment of basic needs, so that persons can live lives of at least minimal decency and avoid unnecessary morbidity and mortality, is the essential priority for just institutions in poor countries" (2005, p.566), thus $c_{D}$ states that a distribution is justified when it brings the maximum number of citizens from $Y_{D}$ to a level $\alpha$ in which their basic needs are fulfilled, with $Y_{D}$ representing the set of citizens which are below level $\alpha$. Formally, $\mathrm{y}_{\mathrm{i}}<\alpha,(\forall) \mathrm{y}_{\mathrm{i}} \in \mathrm{Y}_{\mathrm{P}}, \alpha>0$.

We can immediately observe two major differences between the approaches: 1. $c_{D}$ is focused on maximizing the number of Y-type citizens who will benefit from the distribution, while $c_{P}$ is focused on maximizing the benefits of Y-type citizens and 2. $\mathrm{c}_{\mathrm{D}}$ incorporates a stopping mechanism, i.e. it allows for the possibility 
that set $Y_{D}$ is empty ${ }^{21}$, while in Pogge's case set $Y_{P}$ can never be empty ${ }^{22}$. Thus, Dorsey's theory is applicable only if certain prerequisites are met. We can also observe however, that the approaches are identical from the following point of view: both imply $^{23}$ that the distributing agency $\mathrm{I}^{24}$ precisely identifies all Y-type citizens, meaning both that they do not mistakenly add $\mathrm{X}$-type citizens in set $\mathrm{Y}$ and that and they do not omit any Y-type citizens from set $\mathrm{Y}$.

${ }^{21}$ If there are no individuals who fall under the threshold of basic need fulfillment.

22 In the extreme case in which each individual holds exactly the same amount of resources $X$ and $Y$ would be identical and would contain the entire set of individuals.

${ }^{23}$ We maintain that the assumptions are implied since they are not explicitly discussed in either case, but since an exclusion of facts relating to the capacity of agents to implement normative principles is customary in political philosophy we take it that this is also the case here. If our reading of Pogge and Dorsey's theories is correct and they do indeed imply that individuals in distributive agencies are comprehensively rational, we will show that in some cases the introduction of a bounded rationality can lead to problematic distributions under their principles. If our reading is incorrect and they implicitly argue that the theory generates the same results in a boundedly rational world as much as in a comprehensively rational one, we will show that this view would be erroneous.

${ }^{24}$ In some cases the institution which is responsible for taxation may not be responsible for the redistribution as well but we ignore this aspect here as it does not influence the general result.
In the subsequent section we seek to explore the implications of relaxing these strong assumptions, which are unrealistic because they demand a maximal cognitive capacity uncharacteristic for real-life individuals, by framing the theories in a boundedly rational framework and therefore taking a step in the direction of weakening the ideal perspective of global distributive justice theories.

\subsection{The role of bounded rationality in}

\section{Pogge and Dorsey's distributive patterns}

In order to observe if introducing the assumption of bounded rationality is relevant to the prescriptions of Pogge and Dorsey's theories we will only discuss a single form of manifestation of bounded rationality, namely the capacity of individuals who are responsible for the decision-making process in the distributing agency I to precisely and exhaustively identify the agents in the group who will benefit from the distribution (the Y-type citizens). To use Lipman's (1995) terminology, we will consider that: 1 . the inputs are imperfectly absorbed by the distributing agency, i.e. the information gathered on the economic position of citizens is not perfectly accurate and 2. the process through which individuals in the agency analyze the inputs is cognitively constrained, i.e. the agents evaluating the economic positions of citizens are susceptible to make mistakes in judging 
the individuals which require a distribution of goods or the level of goods required ${ }^{25}$. Thus, we are interested to analyze what the outputs of the distributive agency would be if they conformed to the normative theories advanced by Pogge and Dorsey and if they were the result of imperfections in the input absorption and the decision-making process. In order to operationalize the outputs we will argue that the distributing institution attaches probabilities to the identification of Y-type citizens, the deterministic case (where the institution identifies them with a probability of $100 \%$ ) used by Pogge and Dorsey being reducible to a special case of the probabilistic identification. In order to account for a large number of cases we will use mathematical functions to determine the probability of a correct identification of

\footnotetext{
${ }^{25}$ Various reasons can be brought in support of both assumptions. For instance, input imperfection can be caused by employment on the black market, tax evasion, gaining undeclared income, variability in agricultural production used for subsistence etc., all these forms of unmonitored economic activity preventing the state and the distributive institution from accurately assessing the economic status of citizens. Imperfections in the decision-making process can also have multiple causes, such as low incentives to perform adequately in bureaucracies (for the basic idea behind this assertion see Mueller, 2003, pp.359-385), incapacity to correctly determine the incorporation of citizens into the category of net beneficiaries or net contributors to the redistribution in certain cases, incapacity to correctly aggregate the individual cases into groups targeted for obtaining benefits after the redistribution, etc.
}

Y-type citizens, which will peak at the positions of Y-type citizens and will monotonously decrease as the position of the citizens is further from the position of Y-type citizens, in order to offer a plausible depiction of reality.

For Pogge's GRD approach we define a function of the following type: $\mathrm{f}:[\mathrm{w},+\infty] \rightarrow[0,+\infty], \mathrm{f}(\mathrm{x})=\mathrm{ax}^{2}+\mathrm{bx}+\mathrm{c}$, with $w$ representing the worst-off economic position $^{26}$. The probability that $I$ identifies position $\mathrm{X}_{\mathrm{i}}$ as the worst-off individual is then calculated as a percentage through $\mathrm{p}\left(\mathrm{x}_{\mathrm{i}}\right)=100 \frac{\mathrm{f}\left(\mathrm{x}_{\mathrm{i}}\right)}{\sum_{\mathrm{n}=1} \mathrm{f}\left(\mathrm{x}_{\mathrm{n}}\right)}$. But as previously stated, in order to ground the theory in reality as much as possible, we do not consider that $I$ assigns equal probabilities for every agent to be in the worst-off position, the input absorption and decision-making process being imperfect but still useful for gaining some knowledge regarding genuine economic conditions. Thus, we consider that any function $\mathrm{f}(\mathrm{x})$, defined as above, could theoretically be used for evaluating the probability that a individual with an $\mathrm{x}_{\mathrm{i}}$ amount of goods is in the worst-off position if it satisfies the following condition: 1 . it

\footnotetext{
${ }^{26} w$ can also represent a quintile not a single position, as in Pogge's formulation (1994, p.203). For reasons of simplicity we will consider that $w$ is a single point instead of an interval but the results are not affected by this interpretation.
} 
peaks at $w$ (in mathematical terms $\frac{-\mathrm{b}}{2 \mathrm{a}}=\mathrm{w}$ ) and 2. it decreases monotonically on the entire domain (in mathematical terms $\left.\mathrm{f}^{\prime}(\mathrm{x})<0\right)$. In Figure 1 we can see some of the shapes which the functions, as restricted by the conditions above, can take.

Let us try to explain the reasoning in an informal language. By introducing the bounded rationality assumption we consider that the outputs of the agency which handles the distribution is susceptible to being wrong, in the sense that it is possible for the

Figure 1. Probabilistic functions for identifying worst-off positions under a bounded rationality assumption

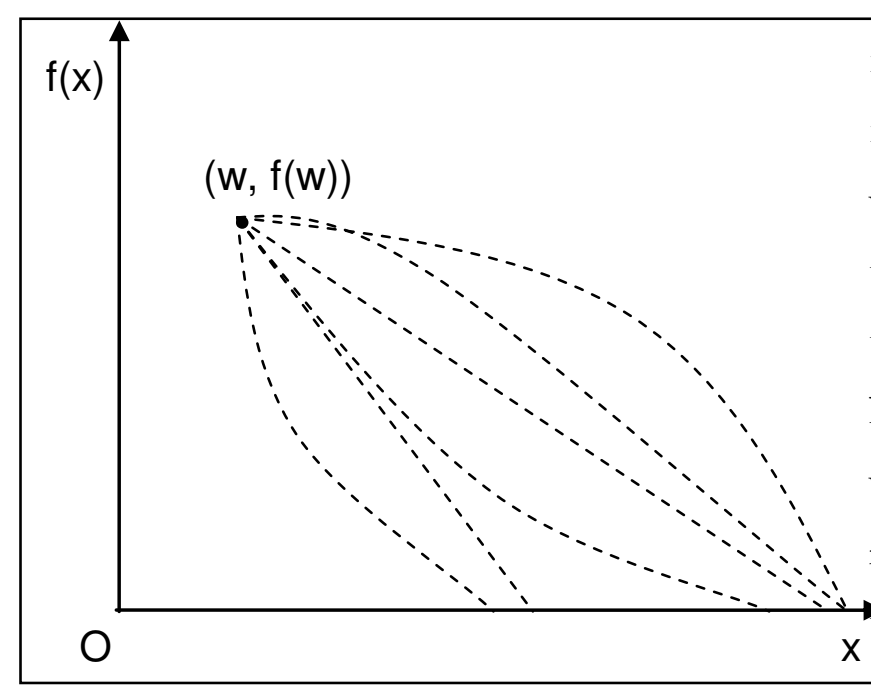

\section{Source: Authors}

agency to distribute goods to some positions which are not in fact worse-off. The purpose of these functions are then to attribute probabilities of obtaining accurate results for each choice made by $I$ regarding the distributive patterns, which are afterwards expressed as a percentage by calculating $\mathrm{p}\left(\mathrm{x}_{\mathrm{i}}\right)$ with the above mentioned formula. The functions are built in such a way as to always assign a higher probability for identification as the worst-off position to individuals who are actually in the proximity of the position and the probability decreases as the actual level of goods possessed by individuals increases. Further, we intentionally allow for an entire class of functions to be eligible for describing the effects of bounded rationality as we cannot identify a single function that could be universally applied precisely because the capacity to collect information and the internal decision-making process varies on a case-by-case basis, from state to state and from agency to agency. Therefore, if we follow Pogge's example of a society which wpuld distribute one third of their GRD through the government and two thirds through other channels such as international NGOs or UN agencies (Pogge, 1994, p.202), we could notice that the differences in their monitoring capacity could for instance lead a superior probability to accurately identify worse-off positions in the case of one of the agencies, either the government due to their detailed access to economic records or perhaps, on the contrary, UN agencies or NGOs due to their superiorly qualified personnel. In mathematical terms, the most efficient agency would be the one with the highest function slope and the one which minimizes the result of $\mathrm{x}_{\mathrm{i}}-\mathrm{w}$ when 
$f\left(x_{i}\right)=0$. A final and essential aspect is that the choice of a specific function in the defined set is irrelevant, as the results obtained will hold if at least one position $\mathrm{x}_{\mathrm{i}}$ exists that will take values from the codomain (and by assuming that agents are boundedly rational this should happen in every case), although depending on the capacity of the distributive institution to obtain accurate identifications, the importance of the results can vary.

Let us consider the following example which will be useful both for a clearer understanding of the way in which bounded rationality would work in the theory and for an understanding of the negative effects which it would bring. Suppose we have a society comprised of only two individuals: $A$ and $B$. Let us further consider that $A$ is in the worst-off economic position as he only has an amount of 5 units of goods while $B$ has 10 units. Let us also consider that the identification of the worstoff position can be made by following the function: $f(x)=-x^{2}+10 x+25, \quad$ with $\mathrm{f}:[\mathrm{w},+\infty] \rightarrow[0,+\infty]$. Since $\frac{-\mathrm{b}}{2 \mathrm{a}}=\frac{-10}{-2}=5$ and $\mathrm{f}^{\prime}(\mathrm{x})=-2 \mathrm{x}+10<0,(\forall) \mathrm{x} \in[5,+\infty)$ we notice that the peak of the function is at the worst-off position and the function monotonically decreases on the entire domain, therefore $\mathrm{f}(\mathrm{x})$ belongs to the class of functions which satisfy the two conditions imposed above. To compute the probabilities with which $I$ would identify each position as being the worst-off we have

$$
p(A)=100 \frac{f(A)}{f(A)+f(B)+f(C)}=100 \frac{50}{50+25+41}=66 .(6
$$

and

$$
\mathrm{p}(\mathrm{B})=100 \frac{\mathrm{f}(\mathrm{B})}{\mathrm{f}(\mathrm{A})+\mathrm{f}(\mathrm{B})}=100 \frac{25}{50+25}=33 .(3) \%
$$

. Therefore, in this situation, the distributive agency would be susceptible to make a mistake in identifying the worst-off positions in one case out of every three. The probability that they would make the correct choice still remains higher than the average however, but what happens when we introduce additional agents? Let us consider that two more actors are introduced to the citizen set: $C$, which in reality has 8 units of the good and $D$ which has 15 units. First let us notice that the probability for $D$ to be chosen as the worst-off position is 0 since $\mathrm{f}(\mathrm{x})$ would not take values in the codomain. $C$ however would be chosen as the worst-off position with a probability of

$$
\begin{aligned}
& \mathrm{p}(\mathrm{C})=100 \frac{\mathrm{f}(\mathrm{C})}{\mathrm{f}(\mathrm{A})+\mathrm{f}(\mathrm{B})+\mathrm{f}(\mathrm{C})}=100 \frac{41}{50+25+41}=35.34 \% \\
& \mathrm{p}(\mathrm{A})=100 \frac{\mathrm{f}(\mathrm{A})}{\mathrm{f}(\mathrm{A})+\mathrm{f}(\mathrm{B})+\mathrm{f}(\mathrm{C})}=100 \frac{50}{50+25+41}=43.1 \%
\end{aligned}
$$

. We can notice therefore that: 1 . as the set of citizens increases the worst-off positions become harder to detect and 2. as more citizens are placed in the vicinity of the worst-off position, the true worst-off positions become harder to detect. 
The practical consequences of these two conclusions are significant. First of all, they state that in large societies, as societies which are in need of a global distribution of goods usually are, the genuinely worst-off positions are very difficult to identify ${ }^{27}$ and that concentrating efforts on finding these positions in order to apply Pogge's principle may be an enterprise which would not be worthy of the costs. Secondly, the fact that worst-off positions are more difficult to indentify in larger societies means that high demographic growth rates in poor societies will make the identification of individuals in worse-off positions exponentially harder to identify. Third, the conclusions also imply that when many citizens in a society are in fact in positions relatively close to those of the worst-off quintile, it is much more difficult to assess which group should be the beneficiary of the distribution. To put it simply, in extremely poor societies it is very difficult to find out which groups are the "poorest" and organize the distributions so as to exclusively target their problems. By adopting the GRD approach with the purpose of maximizing the benefits of the worst-off Pogge therefore ignores second worst-off positions, or second worst-off

27 The worst-off position should not be understood in a narrow way as the position of a single individual, which would of course be quasi-impossible to identify (as the final probability would tend towards 0 even when the slope of the function would be very high). quintiles, which may have severe economic disadvantages as well, but in an extremely poor society and in a boundedly rational world it is, as we previously show, very likely that in many cases the worst-off positions will be incorrectly identified and because there is no distributive mechanism for second or third worst-off quintiles, the poorest members of society will actually be bereft of any distributed goods.

Dorsey's approach requires different conditions than that of Pogge, since Dorsey does not care about worst-off positions, but about those positions which are sufficiently close to the level of minimum basic needs so that a distribution of goods could bring them above the respective level. Thus, let us define a function $\mathrm{f}:[0,+\infty] \rightarrow[0,+\infty], \mathrm{f}(\mathrm{x})=\mathrm{ax}^{2}+\mathrm{bx}+\mathrm{c}$. Similarly to the previous case, any function $\mathrm{f}(\mathrm{x})$ defined in such a way must also satisfy two other conditions in order to generate realistic probabilities: 1.1 . it peaks at $\alpha$ (in mathematical terms $\frac{-\mathrm{b}}{2 \mathrm{a}}=\alpha$ ), where $\alpha$ is the

level of goods required for the minimal satisfaction of basic needs and 2. it increases monotonically on $[0, \alpha)$ and it decreases monotonically on $[\alpha,+\infty)$. Let us also consider that $p\left(x_{i}\right)=100 \frac{f\left(x_{i}\right)}{\sum_{n=1} f\left(x_{n}\right)}$ is the probability that the citizen which holds an 
$\mathrm{x}_{\mathrm{i}}$ amount of goods will be a part of the group benefiting from the distribution. All the observations made when describing the role which bounded rationality would play in Pogge's prescribed distributive pattern, i.e. that the purpose of the function is to faithfully depict real conditions, that bounded rationality allows for an entire class of functions to be used in evaluating the probability that a certain citizens is in proximity to the level of minimum goods, depending on the capacity of the distributive institution to accurately identify the respective positions and that the choice of any function which does not perfectly map every citizen to the exact level of goods held by them can potentially led to problematic consequences for the distributive patterns.

We will also consider an example in order to illustrate this last claim. Let us assume that this time we have a society composed of three citizens: $A, B$ and $C$, possessing 4, 3 and 2 units of goods respectively. Let us further consider that the level of

minimal decency (i.e. the level where citizens can fulfill their basic needs) is $\alpha=5$ and that there are only 3 available goods for distribution $^{28}$. Finally, we will consider that

${ }^{28}$ Remember that Dorsey's approach targets radical poverty specifically, focusing on prioritizing the welfare of some citizens (the citizens who are more likely to achieve a minimum level of subsistence) over others in conditions of scarce resources which

$$
\begin{aligned}
& f(x)=-x^{2}+10 x, \\
& f:[0,+\infty] \rightarrow[0,+\infty] \text {. Since } \frac{-b}{2 a}=\frac{-10}{-2}=5
\end{aligned}
$$

and

$\mathrm{f}^{\prime \prime}(\mathrm{x})=(-2 \mathrm{x}+10)^{\prime}=-2<0 \Rightarrow \mathrm{f}(\mathrm{x})$ is concave , $f(x)$ satisfies the two conditions imposed for the acceptability of the function.

\section{Figure 2. Probabilistic functions for} identifying positions closest to a minimum level of basic needs fulfillment under a bounded rationality assumption

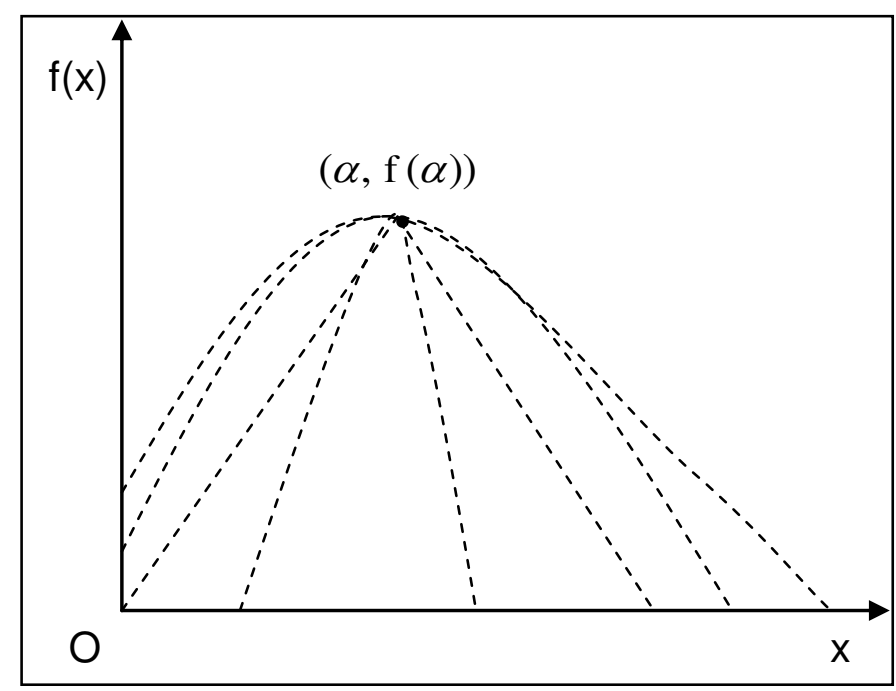

Source: Authors

Thus we can observe that the probabilities attached to the three citizens are:

$$
p(A)=100 \frac{f(A)}{f(A)+f(B)+f(C)}=100 \frac{24}{24+21+16}=39.34 \%
$$$$
p(B)=100 \frac{f(B)}{f(A)+f(B)+f(C)}=100 \frac{21}{24+21+16}=34.42 \%
$$

and

prohibit all the citizens to be brought over the minimum level. 


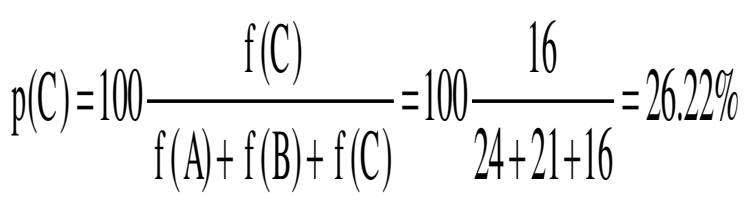

Keep in mind that in this case, the probabilities also refer to proximity between the citizens and the level of basic needs. Since Dorsey's distributive principle argues that we should seek to maximize the number of citizens which are alleviated from extreme poverty it is natural to consider that the closer a citizen is to the level of fulfillment of basic needs, the higher is his chance of being part of the redistributive scheme. In this scenario, $C$ only has about 1 chance in 4 to enter the redistribution scheme but let us examine what would happen if that would indeed be the case. If $C$ gets a part of the 3 units which will be distributed, it automatically means that of the other two agents will not become a part of the distribution mechanism ${ }^{29}$ since there is a scarce amount of resources to be distributed. In a perfectly rational world, Dorsey's principle would prescribe that $A$ should get 1 unit and $B$ should get 2 units, thus both $A$ and $B$ would be lifted to the level of fulfilling basic needs. But in a boundedly rational

\footnotetext{
${ }^{29}$ For the sake of simplicity we will assume that even in a boundedly rational world the distributing institution has the capacity to compile reasonably accurate aggregate data about citizen incomes but that it does not have the capacity to pinpoint the economic status of each individual and it cannot precisely incorporate every individual into the categories.
}

world, where $C$ would enter the distribution scheme with 1 in 4 chances, one of the following 4 scenarios could then be possible: 1. $A$ gets 2 units, $C$ gets 1 unit $^{30} . C$ does not get sufficient resources to be raised to $\alpha$ and $B$ also fails to be raised to the level. Only $A$ is alleviated from poverty, 2. $A$ gets 1 unit, $C$ gets 2 units. The same situation occurs, only $A$ has reached $\alpha, 3$. $B$ gets 2 units, $C$ gets 1 unit. Only $B$ reaches $\alpha$ and 4. $B$ gets 1 unit, $C$ gets 2 units. $B$ gets 4 units in total $(3+1$; he is below $\alpha), C$ gets 4 units in total $(2+2$; he is below $\alpha), A$ gets 4 units in total $(4+0$; he is below $\alpha)$. Although the last case is the most striking one as by following Dorsey's principle in a boundedly rational environment we would arrive at a situation in which none of the 3 citizens are able to reach the level of basic need fulfillment, all cases in which the distributive agency does not perfectly identify both the agents which have a chance to be raised above a certain level of decency and the level of goods required to reach it generates a sub-optimal result. Since the number of alternative cases increases exponentially as the number of citizens increases, we can notice that it would basically be impossible to precisely identify all the positions of the

\footnotetext{
${ }^{30}$ Of course it is also possible that within the distribution mechanism $I$ will incorrectly assess the positions of $A$ and $B$ and distribute 2 units to $A$ and only 1 to $B$ which would also be sub-optimal from Dorsey's point of view.
} 
actors and the level of goods required by them to be alleviated from poverty.

On a practical note, we consider that introducing a bounded rationality assumption in assessing the applicability of Dorsey's maxificing welfarism has a much bigger impact than in Pogge's GRD approach because of the fact that on top of the problems outlined when discussing the latter theory, which also hold in this case, Dorsey asks that the distributive agencies arrive at a much more demanding level of knowledge of each individual in the society as well as the difference between the current economic position of every citizens and the level required for the fulfillment of basic needs. Further, since Dorsey's objective is to maximize the number of citizens which reach the specified levels of decency, the slightest imperfection in the absorption of inputs or the decision-making process would yield sub-optimal results, either by allocating supplementary resources to citizens who are already above the level of decency, by wasting resources on citizens who cannot reach the level at all or can reach it only through a higher distribution of resources than optimal or by not allocating resources to citizens who are in the proximity of the level of decency but have yet failed to reach it.

\section{Conclusions and further discussions}

The results of the paper can be summarized as follows: the assumption that individuals in organizations which allocate goods on the basis of principles established in theories of global distributive justice are boundedly rational generates distorted distributive patterns. Even if we interpret bounded rationality only as an incapacity to obtain full information on the economic situations of citizens and as a cognitive limitation in the decision-making process, there is a significant chance that the theories will miss the groups which they target as beneficiaries for the distribution. In order to observe the effects of the bounded rationality assumption we analyzed Pogge's GRD theory, as it follows distributive principles common to most cosmopolitan theories and Dorsey's maxificing welfarism, as it is predicated on a distinctly consequentialist perspective. We defined a probabilistic function which mapped the level of available goods for individuals (or groups of individuals) to the probability that the distributive agency will correctly identify them as members of the group which is a net beneficiary of the distribution or the group which is a net contributor. We found that the inaccuracies appearing in the identification of citizens with their true group (on the basis of the theories) were enhanced by three factors: 1 . a gently sloping probabilistic function (caused directly by how limited the informational or cognitive 
capacity of the agency is) ${ }^{31}$, 2. a high number of citizens, especially if the positions sought for beneficiary status represented a small groups $^{32}$ and 3. a high accumulation of citizens near the worst-off position in Pogge's case or under the level where they can fulfill their basic needs. The last result is the most important, because it suggests that in cases of extreme poverty, which are paradigmatic cases in which both theories must apply $^{33}$ the probability that the distributive allocations would miss their targets, as specified by the principles is considerably high. Further, as we show at the end of section 4.2. Dorsey's theory appears especially problematic as the slightest amount of noise in the process of allocating the distribution will generate a sub-optimal distribution and in some cases can even subvert the theory completely, by prescribing a pattern in which not even one citizen is lifted to a level where they can fulfill their basic needs.

The first discussion which would ensue is therefore the manner in which the allocation mechanisms should be constructed. Pogge and Dorsey both share the view $^{34}$ that the distribution should

\footnotetext{
${ }^{31}$ This is an assumption not a result but it is also important.

${ }^{32}$ Such as Dorsey's theory would imply.

33 And Dorsey targets specifically these cases.

34 Which is a commonplace among philosophers dealing with distributive justice.
}

concentrate exclusively on a certain set of citizens and ignore all others. In nuce, Pogge maintains that this set should be composed of the poorest individuals in a society, and that individuals who are in other positions (second worst, third worst, etc.) should not receive anything. Dorsey maintains that this set should be composed of individuals who have a significant chance to achieve a minimum fulfillment of basic needs and that individuals who have already achieved this minimum or are so poor that they cannot hope to achieve it should receive nothing. If we consider that the agencies which distribute goods have the complete capacity to identify individuals in each position the categorical distribution is unproblematic. But if we consider that distributive agencies see these sets as diffuse and that they can make mistakes in allocating resources then we should wonder if we should not forego the widely shared view that principles of justice must distribute goods targeted to only certain groups and perhaps adopt a certain type of proportional distributive principle? The principle could be constructed so as to give more weight to some individuals than others, but it would not abandon other groups altogether, who may be in an only slightly more favorable situation in Pogge's theory, or who may be considered too poor to be eligible for an allocation in Dorsey's theory. Although the spatial constraints of the paper prevent us to further elaborate on 
this issue, a preliminary assessment entitles us to argue that at least for Dorsey's idea of poverty alleviation for the greatest number, a proportional allocation would make the potential emergence of perverted results such as 0 poverty alleviation (which is valid for Dorsey's principle under a bounded rationality assumption) almost impossible.

Another important discussion would regard the agency which should be responsible for the distribution, an issue which has already been thoroughly discussed in the literature on distributive justice ${ }^{35}$ and was briefly alluded to in section 4.2. Taking into account the fact that the organization responsible for the allocation of resources can distort the prescribed pattern, would it be better if the distribution was conducted by states toward their own citizens, since they have a better capacity to gather inputs on the economic conditions of their citizens, or by international organizations due to their superior expertise in the allocation process? Although we do not directly approach the issue in the current paper, from this point of view the framing of debates in a boundedly rational assumption could provide fresh support in favor of one of the arguments.

Some other potential research directions which would continue the work began in the paper could extend the debate towards the ideal-type of non-ideal theory by

35 See inter alia, Beitz (1979), Tan (2004), Pogge (2002), Held (2003), Cabrera (2004). analyzing global distributive justice within a full framework of organizational theory, not just under one assumption alteration as in this paper. This type of analysis, whereby we replace a single assumption which characterizes a normative theory is in our view extremely important on its own however, as in many cases, as is the present one, it shows that the principles prescribed by the theory are heavily reliant on unobservable elements which form its background $^{36}$.

To conclude, we consider that in this paper we have shown that by replacing the comprehensive rationality framework with a boundedly rational one in what concerns the ability of the agency which handles resource allocation in global distributive justice theories we obtain results which can considerably subvert the original intention of the principles. The assertion lacks generality, in the sense that it does not say anything about every conceivable global distributive justice theory, but for at least two of them, i.e. Pogge's GRD theory and Dorsey's maxificing welfarism, which we consider representative since the former belongs to

\footnotetext{
${ }^{36}$ For another example of such an analysis see Volacu (2012), where the author replaces the maximization assumption in Rawls' (1971) original position with a satisficient one and argues that in an environment defined as such the agents would not choose the original difference principle but either a constrained difference principle or a constrained version of Rae's (1975) general advantage principle.
} 
the mainstream cosmopolitan strand of global justice and the latter is a perfect example of a consequentialist-derived interpretation of global justice, we believe that we have managed to prove that the prescribed distributive patterns are severely problematic. Even if we have not developed a full account of bounded rationality as applied to the full specter of global distributive justice theories, we trust that, at the minimum, we were able to show that these types of theories can be inextricably dependent on their assumptions and that there is a need to ground these assumptions in genuine empirical circumstances, thereby taking one step further in the direction of non-idealizing theories of justice by making them more sensible to facts.

\section{Bibliographical references:}

Aumann, R. (1997), „Rationality and Bounded Rationality", Games and Economic Behavior, 21, pp.2-14.

Barry, B. (1999), Statism and Nationalism. A Cosmopolitan Critique, New York University Press, New York.

Beitz, C., (1979), Political Theory and International Relations. Princeton University Press, Princeton.

Beitz, C., (2000), "Rawls's Law of Peoples", Ethics, 110 (4), pp. 669-696.

Cabrera, L. (2004), Political Theory of Global Justice: A Cosmopolitan Case for the World State, Routledge, London.
Camerer, C. (1998), "Bounded Rationality in Individual Decision-Making", Social Science Working Paper 1029, California Institute of Technology.

Cohen, G.A. (2003), "Facts and Principles", Philosophy \& Public Affairs, 31 (3), pp.211-245.

Conlisnk, J. (1996), "Why Bounded Rationality?”, Journal of Economic Literature, 34, pp.669-700.

Dorsey, D. (2005), "Global Justice and the Limits of Human Rights", Philosophical Quarterly, 55 (221), pp.562-581.

Dworkin, R. (2000), Sovereign Virtue, Cambridge, Harvard University Press, 2000.

Farrelly, C. (2007), "Justice in Ideal Theory: A Refutation", Political Studies, 55, pp.844-864.

Freeman, S. (2007), Rawls, Routledge, London.

Hamlin, A., Stemplowska, Z. (2012), "Theory, Ideal Theory and the Theory of Ideals", working paper, available online at http://www.cpsaacsp.ca/papers-

2010/Hamlin $\% 20$ and $\% 20$ Stemplowsk a.pdf.

Held, D., (2003), Cosmopolitanism: A Defence, Polity Press, Cambridge.

Jones, B., (1999), "Bounded Rationality", Annual Reviews of Political Science, 2, pp.297-321. 
Lipman, B. (1995), „Information Processing and Bounded Rationality: A Survey", Canadian Journal of Economics, 28 (1), pp.42-67.

Lovell, M. (1986), “Tests of the Rational Expectations Hypothesis", American Economic Review, 76 (1), pp.110-124.

Mollendorf, D. (2002), Cosmopolitan Justice, Westview Press, New York.

Mueller, D.C. (2003), Public Choice (Vol. 3), Cambridge University Press, New York.

Nagel, T. (2005), “The Problem of Global Justice", Philosophy and Public Affairs, 33 (2), pp. 113-147.

Phillips, M. (1985), "Reflections on the Transition from Ideal to Non-Ideal Theory”, Noûs, 19 (4), pp.551-570.

Pogge, T. (1994), "An Egalitarian Law of the Peoples", Philosophy \& Public Affairs, 23 (3), pp.195-224.

Pogge, T. (2001), "Priorities of Global Justice", Metaphilosophy, 32, pp. 6-24.

Pogge T. (2002), World Poverty and Human Rights: Cosmopolitan Responsibilities and Reforms, Polity Press, London.

Rae, D., (1975), "Maximin Justice and an Alternative Principle of General Advantage", American Political Science Review, 69 (2), pp.630-647.

Rawls, J., (1971[1999]), A Theory of Justice (revised edition), Belknap Press, Cambridge, Massachusetts.
Rawls, J. (1993), "The Law of the Peoples", Critical Inquiry, 20 (1), pp.36-68.

Rawls, J. (1999), The Law of the Peoples, Harvard University Press, Cambridge.

Reidy, D. (2004), "Rawls on International Justice: A Defense", Political Theory, 32 (3), pp.291-319.

Selten, R. (1998), "Features of experimentally observed bounded rationality", European Economic Review, 42, pp. 413-436.

Selten, R. (1999), „What is Bounded Rationality?”, SFB Discussion Paper B-454, online at: http://www.wiwi.unibonn.de/sfb303/papers/1999/b/bon nsfb454.pdf.

Sen, A., (1997), "Maximization and the Act of Choice", Econometrica, 65 (4), pp.745-779.

Simmons, A. (2010), "Ideal and Nonideal Theory", Pbilosopby \& Public Affairs, 38(1), pp.5-36.

Simon, H., (1955), “A Behavioral Model of Rational Choice", Quarterly Journal of Economics, 69 (1), pp.99-118.

Simon, H. (1976), Administrative Behavior, Free Press, New York.

Simon, H. (1978), "Rationality as Process and as Product of Thought", American Economic Review, 68 (2), pp.1-16.

Tan, K.-C. (2004), Cosmopolitanism, Nationalism and Patriotism, Cambridge University Press, Cambridge. 
Tversky, A., Kahneman, D. (1974), "Judgment under Uncertainty:

Heuristics and Biases", Science, 185 (4157), pp.1124-1131.

Tversky, A., Kahneman, D. (1979), „Prospect Theory: An Analysis of Decision Under Risk”, Econometrica, 47 (2), pp.263-292.

Valentini, L. (2012), "Ideal vs. Non-ideal Theory: A Conceptual Map", Philosophy Compass, 7 (9), pp. 654-664.

Volacu, A. (2012), "On the Optimal Choice Criterion in a Satisficiency-Based Original Position", presented at the Center for Research in Applied Ethics, Faculty of Philosophy (University of Bucharest), 19 October 2012. 